\title{
Changes in the timing and duration of the near-surface soil freeze/thaw status from 1956 to 2006 across China
}

\author{
K. Wang ${ }^{1}$, T. Zhang ${ }^{1}$, and X. Zhong ${ }^{2}$ \\ ${ }^{1}$ Key Laboratory of Western China's Environmental Systems (Ministry of Education), College of Earth and Environmental \\ Sciences, Lanzhou University, Lanzhou, 730000, China \\ ${ }^{2}$ Laboratory of Remote Sensing and Geospatial Science, Cold and Arid Regions Environmental and Engineering Research \\ Institute, Chinese Academy of Sciences, Lanzhou, 730000, China \\ Correspondence to: T. Zhang (tjzhang@lzu.edu.cn)
}

Received: 27 May 2014 - Published in The Cryosphere Discuss.: 15 July 2014

Revised: 02 June 2015 - Accepted: 06 June 2015 - Published: 24 June 2015

\begin{abstract}
The near-surface soil freeze/thaw status is an important indicator of climate change. Using data from 636 meteorological stations across China, we investigated the changes in the first date, the last date, the duration, and the number of days of the near-surface soil freeze over the period 1956-2006. The results reveal that the first date of the near-surface soil freeze was delayed by about 5 days, or at a rate of $0.10 \pm 0.03$ day $\mathrm{yr}^{-1}$, and the last date was advanced by about 7 days, or at a rate of $0.15 \pm 0.02$ day $^{-1} r^{-1}$. The duration of the near-surface soil freeze decreased by about 12 days or at a rate of $0.25 \pm 0.04$ day $\mathrm{yr}^{-1}$, while the actual number of the near-surface soil freeze days decreased by about 10 days or at a rate of $0.20 \pm 0.03$ day $\mathrm{yr}^{-1}$. The rates of changes in the near-surface soil freeze/thaw status increased dramatically from the early 1990s through the end of the study period. Regionally, the changes in western China were greater than those in eastern China. Changes in the nearsurface soil freeze/thaw status were primarily controlled by changes in air temperature, but urbanization may also play an important role.
\end{abstract}

\section{Introduction}

The near-surface soil freeze/thaw state is related to the timing and duration of cold/warm seasons, and is an important indicator of climate change (Zhang et al., 2001). During the past few decades, many studies have focused on the dynamics of the near-surface soil freeze/thaw status and the interactions between the ground surface and the atmosphere.
These studies have shown that changes in the near-surface soil freeze/thaw status are interrelated, and soil freeze/thaw affects hydrological processes (Cherkauer and Lettenmaier, 1999; Niu and Yang, 2006; Rempel, 2012), ecological processes (Schimel and Mikan, 2005; Tagesson et al., 2012), and soil microbial processes (Lloyd and Taylor, 1994; Gilichinsky and Wagener, 1995; Edwards and Jefferies, 2013).

Variations in the timing and duration of the near-surface soil freeze/thaw state have been widely investigated using a range of approaches, including remote sensing and in situ observations, across spatial-temporal scales ranging from regional to global. Menzel et al. (2003) used data from 41 meteorological stations across Germany (from 1951 through 2000) to investigate soil frost dynamics. Their results showed that the freeze-free period was extended with increasing air temperature. Henry (2008) used observations from 31 stations across Canada to examine soil freeze dynamics and found that the number of days of the near-surface soil freeze declined from 1966 through 2004. Using long-term data from three stations in Indiana, USA, Sinha and Cherkauer (2008) found that the number of soil freeze days had significantly decreased at the central and southern study sites, but the nearsurface soil temperature at the northernmost site showed a significant decrease in the cold season due to a decrease in snow depth. Anandhi et al. (2013) carried out a more detailed analysis of frost indices at 23 stations across Kansas, USA, and found that the first date and the last date of freezing occurred later and earlier, respectively, over their study period. 
Numerous studies have reported significant improvements in monitoring the soil freeze/thaw status. NASA is launching the Hydrosphere State Mission as part of the Earth System Science Pathfinder Program (ESSP) to improve satellite monitoring of global land freeze/thaw status and soil moisture (Entekhabi et al., 2004). In China, a multi-scale monitoring network has been established on the Qinghai-Tibetan Plateau (Yang et al., 2013). Fifty-six stations have been installed in cold and high-elevation regions to enhance monitoring of soil temperature and moisture and hence to support remote sensing data and large-scale climate modeling ( $\mathrm{Su}$ et al., 2011; Yang et al., 2013).

In this study, we use ground-based station data to investigate the long-term spatiotemporal variation in the timing and duration of the near-surface soil freeze/thaw across China over the period 1956-2006. Using data from 636 stations, we examine the first date, last date, duration, and actual number of days of the near-surface soil freeze, as well as the spatial characteristics of these variables across China. Finally, we further investigate the response of the near-surface soil freeze/thaw status to climate changes over the past few decades.

\section{Data and methods}

We define the soil freeze day as a day with a minimum temperature of or below $0^{\circ} \mathrm{C}$ at the ground surface (Henry, 2008). Data used for this study include daily minimum ground-surface temperature and mean annual air temperature (MAAT) obtained from the China Meteorological Administration (CMA, 2007a).

Temperature monitoring was conducted each day by trained professional technicians at all meteorological stations across China. Ground surface temperatures were measured with a mercury ball thermometer (ball diameter of about $3 \mathrm{~mm}$ ). Although measurement standards state that half of the thermometer sensor should be buried in the ground and the other half exposed to the air, in practice, the sensors were usually buried more than halfway and were often colored white to reduce solar heating. When the ground was covered by snow, the sensor was moved to the snow surface. Thus snow surface temperature was measured rather than the ground surface temperature. In this case, it is assumed that soils near the ground surface are in a frozen state (Zhang, 2005). Daily minimum temperatures were measured using a minimum temperature thermometer, which recorded the daily minimum temperature once a day although it could not record the time when it occurred. Daily minimum temperature was reported at 20:00 Beijing Time. Ground surface temperatures were measured four times per day (02:00, 08:00, 14:00, and 20:00 Beijing Time) and averaged as a daily mean. The thermometers at the study stations have an accuracy of $0^{\circ} \mathrm{C}$ and should be calibrated at least once a year (CMA, 2007b). None of the thermometers were replaced dur- ing the study period. The large majority of the meteorological stations remained geographically stable over the study period (Ma et al., 2009); however, information is not available for those stations with a history of location changes. We believe that the effect of station movement on our results is minimal.

Our daily surface temperature data set was created with thorough data quality control. On daily timescale, we checked the consistency of the temperature time series by cross-referencing temperature values with the day before and the day after the checking day.

Annual values of the first and last date, duration, and actual number of days of the near-surface soil freeze were calculated for each year beginning on 1 July and ending on 30 June of the next year, in order to cover the entire period with potential freezing events. The anomalies of each variable were calculated over the entire study period after removing the long-term average (1 July 1961 through 30 June 1991) across China. We used linear regression to investigate the trend of changes for each variable. Stations with statistically significant changes $(P<0.05)$ were kept in the analysis. We also compared the linear trends of the freeze/thaw variables with latitude and elevation to investigate the geographic characteristics of the freeze/thaw changes. In addition, we used the quantile-quantile method to ensure that the linear hypothesis was statistically appropriate (John, 2006; David, 2009).

The first date (FD) and last date (LD) of the near-surface soil freeze are defined as the first and last date after 1 July on which the daily minimum ground surface temperature is at or below $0^{\circ} \mathrm{C}$. The duration (DR) of the near-surface soil freeze is defined as the time span between the first and last date of the near-surface soil freeze. It is common for the nearsurface soil not be continuously frozen during the period between the first date and the last date of freeze. Thus, we further define the actual number of the near-surface soil freeze days (NF) by counting the number of days with a daily minimum ground surface soil temperature at or below $0^{\circ} \mathrm{C}$.

Not all of the meteorological stations in this study have continuous data over a 30-year period (1 July 1961 through 30 June 1991). Generally, 8 or less missing years $(<25 \%$ of the 30-year period) are permitted in a calculation of the long-term mean (Jones and Hulme, 1996). The combined time series of anomalies was generated by using data from all available stations with at least 22 years of records. In this study, we applied a thorough data quality control approach to ensure the reliability and consistency of results by station and year. Firstly, study years with 365 daily records were utilized in the annual indices. Secondly, we detect the outliers with 3 standard deviations $(3 \sigma)$ from its long-term mean as described by Polyakov et al. (2003) and Park et al. (2014). To ensure a specific outlier which may be questionable, we check the outlier with neighboring stations within $200 \mathrm{~km}$. If data from the neighboring stations are normal, we consider this data point as an outlier and remove it from the time series. Otherwise, if there are at least two and/or more neigh- 
boring stations that have data points with 3 standard deviations or higher, we consider these data points as representative of the true values and keep them in the analysis. Finally, we plotted and screened each individual time series to identify questionable data points. This resulted in 636 meteorological stations being included in this study (Fig. 1).

\section{Results}

\subsection{Climatology of the timing and duration of the near-surface soil freeze}

Long-term mean of the timing and duration of the nearsurface soil freeze was performed over a 30-year period (1 July 1961 through 30 June 1991) to reveal the spatial patterns of climatology (Fig. 2). Regions south of $24^{\circ} \mathrm{N}$ were considered as freeze-free regions because freeze events were generally scarce in those areas.

The timing and duration of the near-surface soil freeze varied greatly across China. FD occurred from July of the current year through January of the next year across China. LD occurred from January of the next year through June of the next year. DR ranged from 2 weeks or less in southern China through almost the entire year on the Qinghai-Tibetan Plateau. The maximum of NF was up to 315 days, which was significantly less than the maximum of DR because of the discontinuous freeze events during the freeze period.

The earliest and latest dates of the near-surface soil freeze occurred in July of the current year and in June of the next year on the Qinghai-Tibetan Plateau. NF was up to 10 months on the plateau.

Our results showed an understandable latitudinal zonal pattern in eastern China, and a significant elevation correlation in western China. Maximum elevations in eastern China are about $1500 \mathrm{~m}$ in eastern China and $5000 \mathrm{~m}$ in western China due to the location of the Qinghai-Tibetan Plateau. Overall, NF increased about 10 days per degree of latitude in eastern China and about 5 days per $100 \mathrm{~m}$ of elevation in western China. The DR increased about 9 days per degree of latitude in eastern China and 6 days per $100 \mathrm{~m}$ of elevation in western China.

\subsection{Changes in the first date of the near-surface soil freeze}

Overall, FD departures from its long-term mean showed a significant increase across China by nearly 5 days, or a trend of $0.10 \pm 0.03$ day $_{\mathrm{yr}^{-1}}$, for the period 1956-2006 (Fig. 3a). We found that the near-surface soil started to freeze later due to a general warming in the fall season across China during the study period. The coefficient of determination, $R^{2}=0.25$, means that one-fifth of the total variability in the FD can be explained by the regression equation. Variations can be mainly broken into two periods: before and after the early 1970s. FD anomalies during the mid-1960s

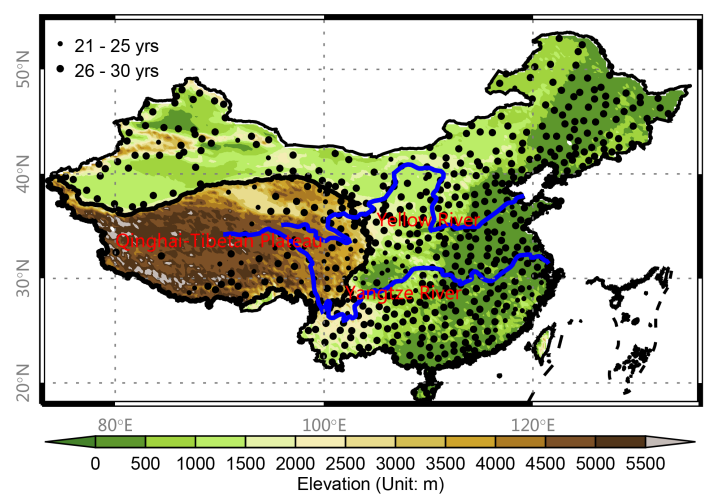

Figure 1. Map of meteorological stations across China used in this study. Background reflects elevation and sizes of circles reflect data availability during the period from July 1971 to June 2001. Boundary line of Qinghai-Tibetan Plateau is from Zhang et al. (2014).

through the mid-1970s are the lowest in the study period. A delay in FD (0.22 day $\left.\mathrm{yr}^{-1}\right)$ started in the early 1970 s when a short cold period ended. Meanwhile, a large delay in FD $\left(0.72 \pm 0.17\right.$ day $\left.\mathrm{yr}^{-1}\right)$ occurred after the early $1990 \mathrm{~s}$ (Fig. 3a); FD had occurred approximately 10 days later since the early 1990 s with $R^{2}=0.60$, implying that about $60 \%$ of the total variability in the FD can be explained by the linear trend.

Over the study period, the 126 study stations showed a significant trend in FD delay in autumn (Fig. 3b). Most stations showed long-term FD delays, except for a few stations where FD was advanced. Among about 84 of the 126 stations, the FD delay was $<0.25$ day $\mathrm{yr}^{-1}$ (Fig. 3b). When comparing stations in western China and eastern China (east and west of $110^{\circ} \mathrm{E}$ ), we found that the FD delay was greater in the west than in the east. A dry environment in western China may be an important element enhancing the changes in FD because latent heat is less when moisture is low. FD at stations surrounding or on the Qinghai-Tibetan Plateau was delayed by $>0.5$ day $\mathrm{yr}^{-1}$ (Fig. 3b).

\subsection{Changes in the last date of the near-surface soil freeze}

The LD was advanced in spring significantly over the period of 1956-2006, by about 7 days, or a trend of $0.15 \pm 0.02$ day $\mathrm{yr}^{-1}$ (Fig. 4a). This indicates that warming spring seasons result in an earlier end of the near-surface soil freeze. Approximately $46 \%$ of the total variability in the LD can be explained by the linear trend. Variations in LD are divided into two periods: before and after the early 1990s. LD occurred slightly earlier from 1956 through 1991. The highest deviated from the long-term mean occurred during 1965-1980. A rapid advancement of LD appeared after the early 1990 s, with a linear trend of $0.60 \pm 0.14$ day $_{\mathrm{yr}^{-1}}$; i.e., LD has occurred earlier by about 9 days since 1992 . 

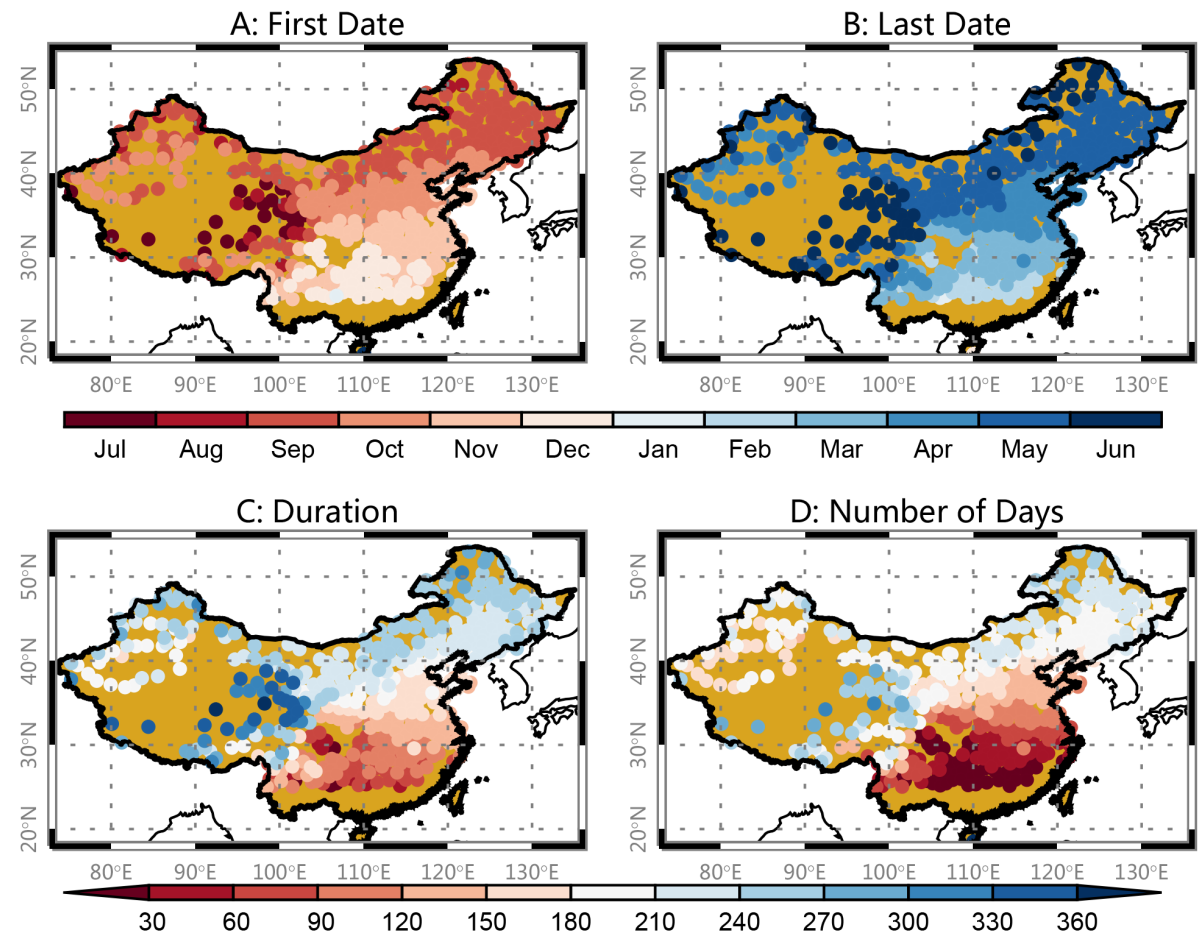

Figure 2. Climatology of the first date (a), the last date (b), the duration (c) and the number of days (d) of the near-surface soil freeze/thaw status across China. The 30-year reference period was from July 1961 through June 1991.

LD changed significantly at $30 \%$ (202 stations) of all stations (Fig. 4b). This percentage is larger than that of the stations with a significant delay in FD. Among 160 stations, LD was advanced by about 0.30 day $\mathrm{yr}^{-1}$ (Fig. $4 \mathrm{~b}$ ). LD changes in western China were larger than those in eastern China. Overall, FD and LD were significantly delayed and advanced, respectively, at 85 stations. These stations show a delayed onset of autumn soil freeze and an earlier ending of the spring soil freeze over the study period.

\subsection{Changes in the duration of the near-surface soil freeze}

Over the period from 1956 through 2006, DR was shortened

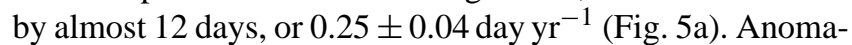
lies during 1966-1980 were higher than the rest of the study period. The most significant decrease in DR appeared mainly after the 1970s $\left(0.45\right.$ day $\left.\mathrm{yr}^{-1}\right)$. Since the early 1990s, DR has decreased sharply $\left(1.18 \pm 0.20\right.$ day $\left.\mathrm{yr}^{-1}\right)$ (Fig. 5a), by almost 16 days. The overall variation in DR $\left(0.25\right.$ day $\left.\mathrm{yr}^{-1}\right)$ is a combination of changes in FD $\left(0.10\right.$ day $\left.\mathrm{yr}^{-1}\right)$ and LD $\left(0.15\right.$ day $\left.\mathrm{yr}^{-1}\right)$. For example, the increase in DR (12 days) corresponds to the delay of FD by 5 days and the advance of LD by 7 days.

235 study stations showed a significant decrease in DR of $<0.50$ day $\mathrm{yr}^{-1}$ (Fig. 5b). Most stations showed a long-term decrease in DR, except for three stations where DR showed a slight increase. DR decreased more in western China than in eastern China. This general decrease in DR indicates a shortening frost period in the near-surface soil across China over our study period.

\subsection{Changes in the number of days of the near-surface soil freeze}

It is important to realize that near-surface soil may not be continuously frozen during the period from the first date to the last date of the near-surface freeze, especially in mid- or low-latitude sites. We determine NF by counting the actual number of days with minimum soil temperature $\leq 0^{\circ} \mathrm{C}$.

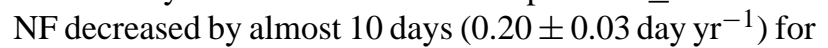
the period 1956-2006 (Fig. 6a). The trend in NF is similar to but smaller than that in DR (compare to Fig. 4a). A statistically significant increase in NF has occurred since the early 1970s. During the period from 1971 through the early 1990s, NF decreased slightly $\left(0.27\right.$ day $\left.\mathrm{yr}^{-1}\right)$. The NF decrease for the period from 1971 through the end of our study period

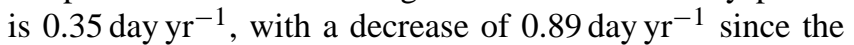
early 1990s (Fig. 6a). The actual number of freeze days in near-surface soil decreased by 12 or more days over our study period.

At 344 stations (about $54 \%$ of all study stations), NF varied significantly over the study period (Fig. 6b). Although a few stations in western China showed an increasing trend in NF, the remaining stations showed a significant decreasing trend, with decreasing trends ranging from 0.50 to 

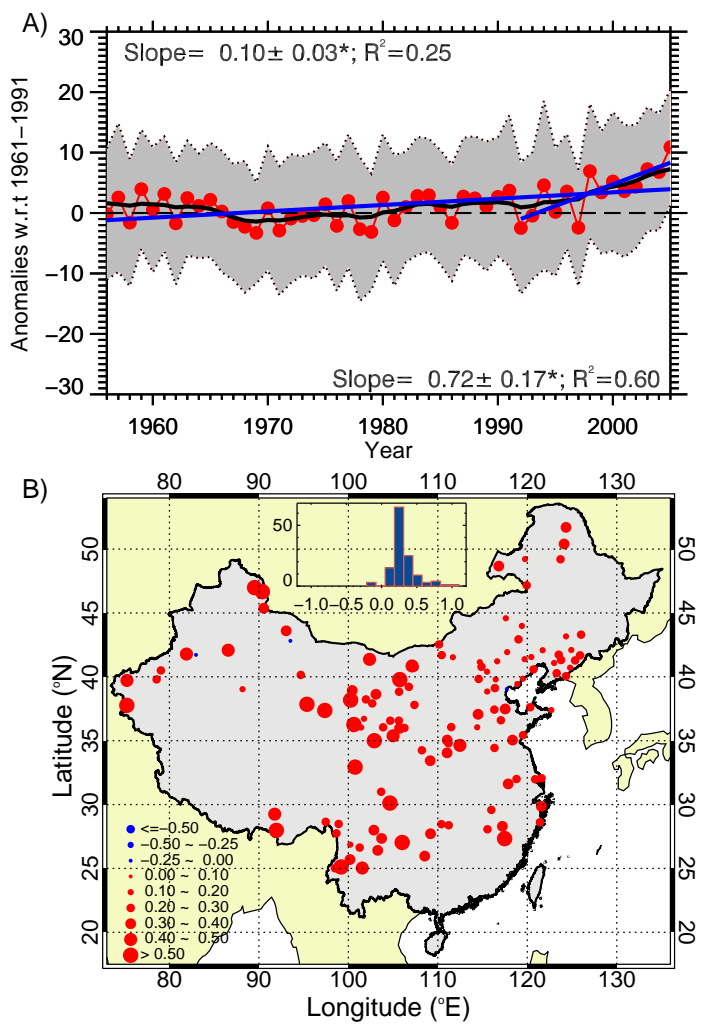

Figure 3. (a) Composite of anomalies for the first date (FD) from 1956 through 2006 across China. The composite of anomalies for FD was simply an average of anomaly across all available stations for each year. The solid circles represent the composite anomaly for a year. The shaded area represents 1 standard deviation from the mean for each year. The thick line represents a smoothed curve by a cut-off frequency of 0.091 . The thick straight lines are linear regression trends. Asterisk indicates a statistically significant trend with a $95 \%$ or higher confidential level. (b) Rate of linear trends in FD from 1956 through 2006 for stations with $95 \%$ or higher confidential level across China; center-top panel is the histogram the rate of changes in FD.

0.20 day $\mathrm{yr}^{-1}$ (Fig. 6b). This general decrease in NF indicates a shortening cold season across China.

\subsection{Variations in the near-surface soil freeze with latitude and elevation}

Changes in the near-surface soil freeze are primarily controlled by elevation in western China and by latitude in eastern China. In western China, the rate of change in FD increases as elevation increases (Fig. 7a), which implies that changes in FD in higher-elevation regions are greater than those over lower elevation areas. The rate of change in NF decreases (becomes more negative) as the elevation increases (Fig. 7b). In other words, the absolute magnitude of the rate of NF change increases with increasing elevation. This implies that NF decreases faster in the higher-elevation areas than in the lower-elevation regions, which is consistent with
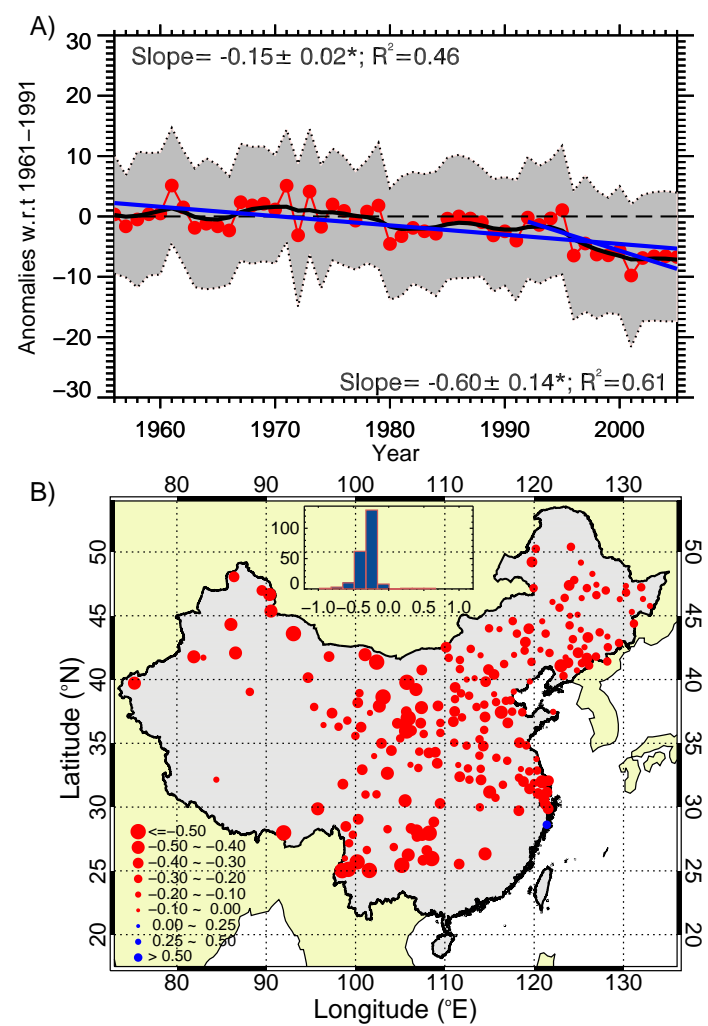

Figure 4. Same as Fig. 3 except for the last date of the near-surface soil freeze.

the FD changes. However, changes in LD and DR with elevation are not statistically significant in western China (not shown).

Over eastern China, the rates of change in LD, DR, and NF are significantly correlated with latitude. The rates of change in LD (Fig. 7c), DR (Fig. 7d), and NF (Fig. 7e) increase as latitude increases, which demonstrates that the magnitude of changes in LD, DR, and NF is greater in lower-latitude regions than in higher-latitude regions. Lower-latitude regions are more sensitive to freeze/thaw timing and duration because soils at more southerly latitudes are closer to the freezing point in cold seasons. Under warming climate conditions, changes in soil temperature in southern regions have a greater impact on the timing and duration of the near-surface soil freeze. The FD is not significantly correlated with changes in latitudes in eastern China (not shown). However, the rate of NF change increases (becoming less negative) with elevation in eastern China (Fig. 7f). In other words, the magnitude of NF changes decreases with elevation in eastern China. This is contradictory to the rate of NF changes in western China. We believe that there are two possible explanations: (i) changes in soil freeze in eastern China are primarily controlled by latitudes; (ii) elevation changes in eastern China are relatively small compared with those in western China. Elevation difference in western China is up to $5000 \mathrm{~m}$ (Fig. 7b), while in eastern China, the difference is about $1500 \mathrm{~m}$ (Fig. 7f). 


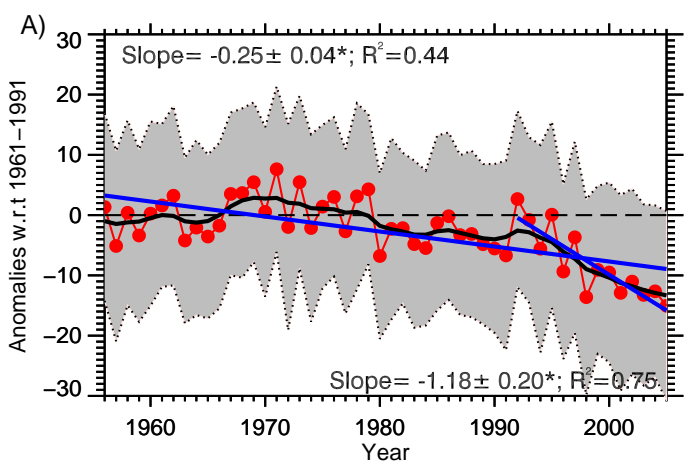

B)

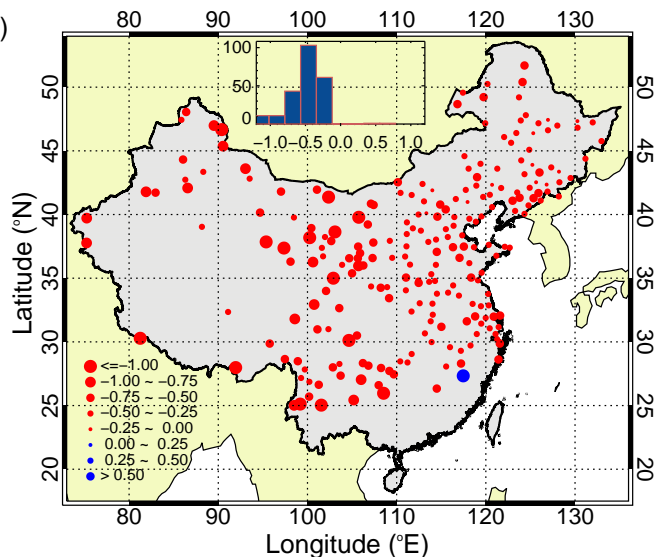

Figure 5. Same as Fig. 3 except for the duration of the near-surface soil freeze.

\subsection{Effects of air temperature on the near-surface soil freeze}

Air temperature is an important factor that affects the nearsurface soil freeze/thaw dynamics. The FD increased as mean autumn (September, October and November) air temperature increased at a rate of about $3.86 \pm 0.52$ day $^{\circ} \mathrm{C}^{-1}$ (Fig. 8a), implying that the FD was delayed in autumn. This positive correlation between FD and mean autumn air temperature implies that overall delay in FD indeed reflects autumn warming in recent decades across China. The LD decreased at a rate of $2.82 \pm 0.72$ day $^{\circ} \mathrm{C}^{-1}$ as mean spring (March, April, and May) air temperature increased (Fig. 8b), indicating that the LD advanced in spring as mean spring air temperature increased over the past several decades across China. As a result, the DR and NF are inversely correlated with MAAT (Fig. 8c and d) i.e., the DR was shortened and the NF was decreased with increased MAAT, as expected. However, the DR was shortened at a rate of $7.75 \pm 1.31$ day ${ }^{\circ} \mathrm{C}^{-1}$, while the NF decreased at a rate of $6.61 \pm 1.06$ day ${ }^{\circ} \mathrm{C}^{-1}$; the rate of NF change is about $15 \%$ less than that of the DR change. Changes in DR are mainly controlled by changes in FD and LD. In other words, changes in DR are mainly controlled by changes in autumn and spring air temperatures, while changes in NF are controlled not only by changes in
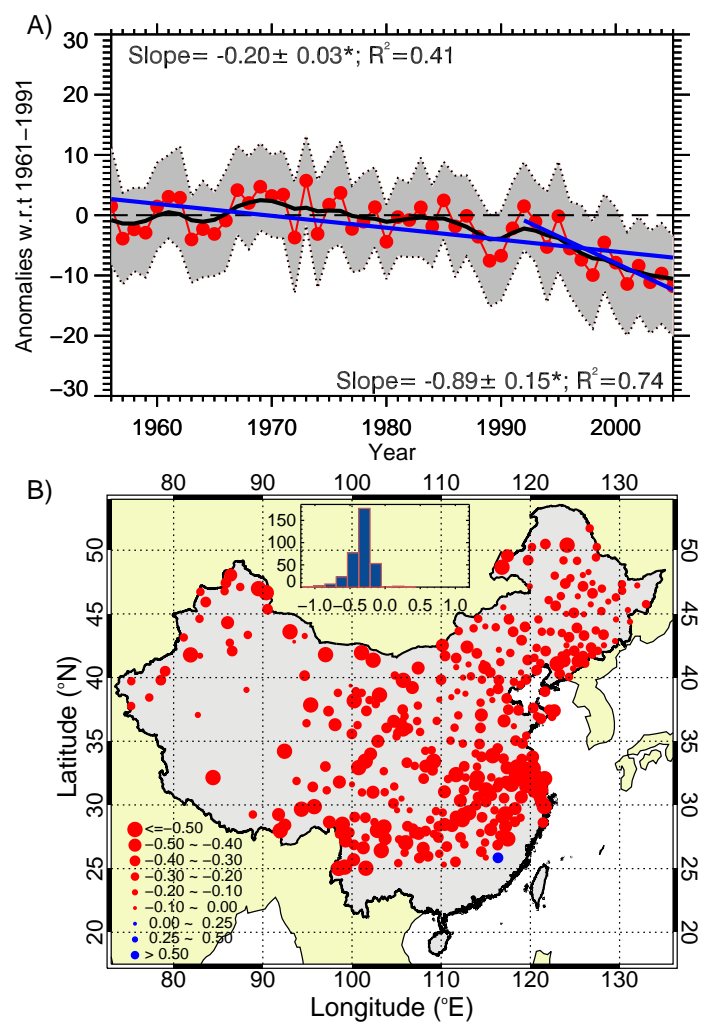

Figure 6. Same as Fig. 3 except for the number of days of the nearsurface soil freeze.

autumn and spring air temperatures, but also by changes in air temperature during the entire cold season.

The freeze index of air temperature (AFI) is a measure of the combined magnitude of temperatures below $0^{\circ} \mathrm{C}$ from 1 July in the current year through 30 June in the next year, in order to cover the entire freeze period (Zhang et al., 2001). Overall, DR and NF are positively correlated with freeze index, as expected (Fig. 9). During the entire period, DR was lengthened and NF was increased with increasing freeze index across China. Similar to the correlations with mean annual air temperature, the rate of the DR extension is larger than the rate of NF increase with the freeze index. In addition, the variations of NF and DR can be explained about 21 and $26 \%$ by the freeze index of air temperature, which are significantly less than that by MAAT (Fig. $8 \mathrm{c}$ and d). This is because the freeze index reflects not only the freeze period but also the magnitude of freeze temperatures in air; in other words, a higher freeze index can not be singly correlated to a longer freeze period because the freeze index value may be caused by a greater magnitude of the cold temperatures. 

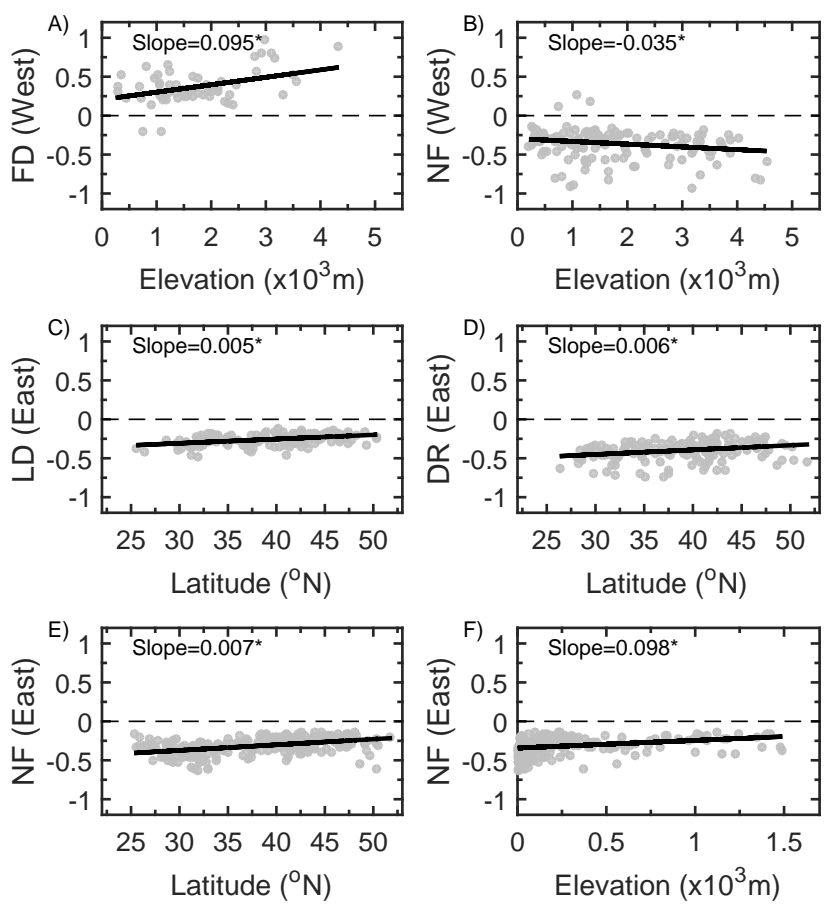

Figure 7. Trends of the first date (FD), the last date (LD), duration (DR), and number of freeze days (NF) at stations in western China (in first row, longitude $\leq 110^{\circ} \mathrm{E}$ ) and in eastern China (in second and third rows, longitude $\left.>110^{\circ} \mathrm{E}\right)$ against latitude $\left({ }^{\circ} \mathrm{N}\right)$ and elevation $\left(\times 10^{3} \mathrm{~m}\right.$ a.s.l.). Each point represents one station, with a statistically confidential level of $95 \%$ or higher. Solid cycles are data points, and lines are linear fitted lines. Asterisk indicates a significant trend at the $95 \%$ confidential level or higher.

\section{Discussion}

\subsection{Comparisons with previous results}

The timing and duration of the near-surface soil freeze were investigated using ground-based measurements from 636 stations across China from 1956 through 2006. Primary results indicate that the FD occurred later, while the LD became earlier, resulting in a decrease in both the duration and number of days of the near-surface soil freeze in China.

FD was delayed by about 5 days $\left(0.10\right.$ day $\left.\mathrm{yr}^{-1}\right)$ over the entire study period, as a result of warming climate. Similar results have been found on the Qinghai-Tibetan Plateau ( $\mathrm{Li}$ et al., 2012), in Indiana, USA (Sinha and Cherkauer, 2008), and in Kansas, USA (Anandhi et al., 2013). However, results from this study indicate that the rate of FD change from the early 1990s to 2006 across China was about 0.72 day $\mathrm{yr}^{-1}$, while $\mathrm{Li}$ et al. (2012) found that the rate of FD change was about 0.50 day $\mathrm{yr}^{-1}$ over the Qinghai-Tibetan Plateau from 1988 through 2007. Their results were obtained from passive microwave satellite remote sensing data, which may have a large uncertainty and may underestimate the autumn warming on the Qinghai-Tibetan Plateau.
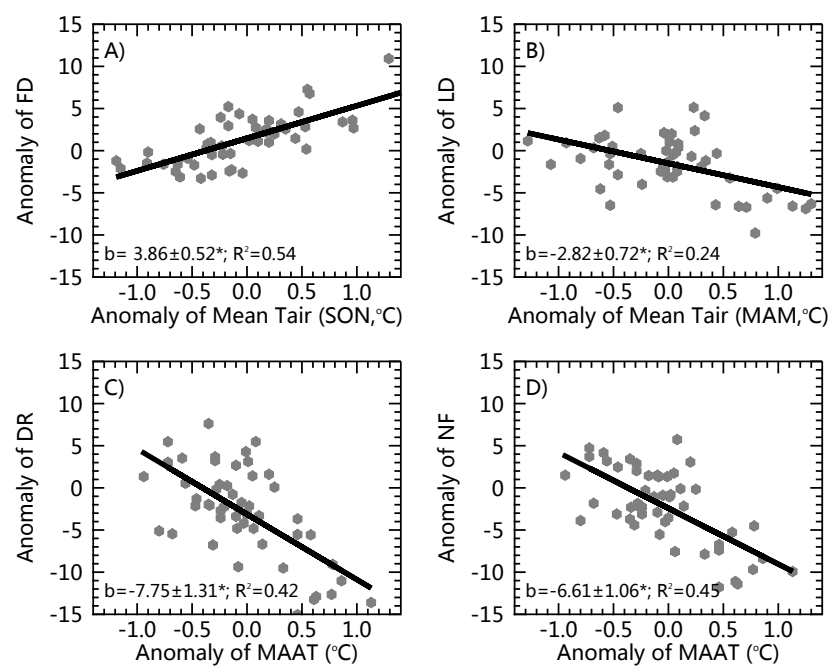

Figure 8. Relationship between (a) anomalies of mean autumn air temperature (September through November) and the first date (FD), (b) anomalies of mean spring air temperature (March through May) and the last date (LD), (c) anomalies of mean annual air temperature (July through June in the next year) and duration (DR), and (d) number of days (NF) from 1956 through 2006 across China. All regression lines have a statistically significant trend with at least a $95 \%$ confidential level.

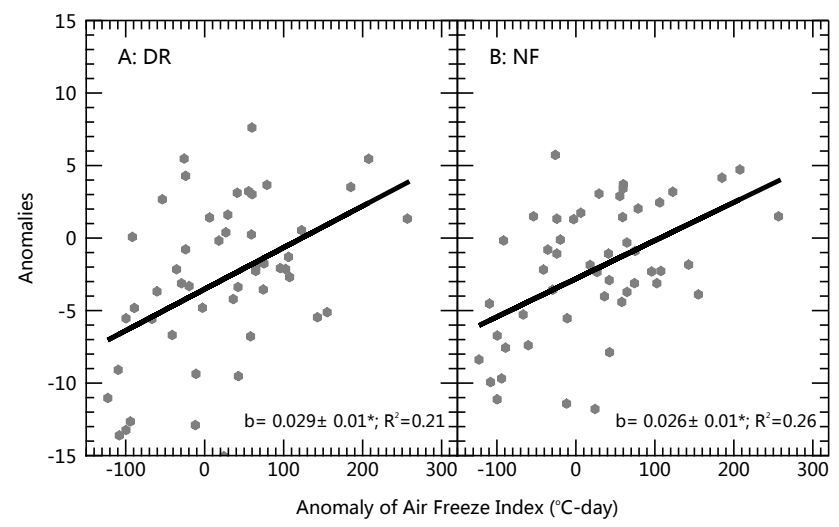

Figure 9. Relationship between anomalies of the freeze index of air temperature (AFI) and (a) duration (DR), and (b) number of days (NF) from 1956 through 2006 across China. All regression lines have a statistically significant trend with at least a $95 \%$ confidential level.

Similarly, LD occurred approximately 7 days earlier $\left(0.15\right.$ day $\left.\mathrm{yr}^{-1}\right)$ over our study period. Li et al. (2012) showed a later date of soil freeze by about 14 days (or 0.70 day $\mathrm{yr}^{-1}$ ) from 1988 to 2007 . We found more change in the LD in

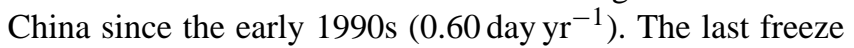
date in Kansas, USA, occurred earlier by $0.01-0.19$ day $\mathrm{yr}^{-1}$ from 1919 through 2009 (Anandhi et al., 2013), and this is similar to our results for our study period.

Our results indicate that DR and NF decreased by 12 and 10 days, respectively, from 1956 to 2006 and have decreased 
sharply since the early 1990s. We also found significant regional diversity. On the Qinghai-Tibetan Plateau, the number of freeze days decreased by 1.68 day $\mathrm{yr}^{-1}$ during the period 1988-2007 (Li et al., 2012). This corresponds to our results (Fig. 6a). The number of freezing days in Kansas, USA,

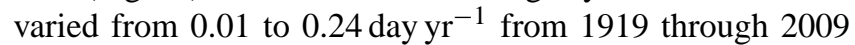
(Anandhi et al., 2013), which is similar to our results for our study period.

Increasing air temperature significantly influences the timing and duration of near-surface soil freeze. Warming ground can play a significant role in carbon cycles in landatmosphere processes (Koven et al., 2011; Schuur et al., 2009; DeConto et al., 2012; Tagesson et al., 2012), but the mechanism of this role is complex and not clear, even though studies have found correlations between growing season carbon fluxes and increased soil temperature, particularly in the high Arctic (Tagesson et al., 2012; Mastepanov et al., 2008; Heimann and Reichstein, 2008). Other studies have shown that increasing temperature results in the lengthening of the growing season and improved productivity (Kimball et al., 2006; Barichivich et al., 2013). These effects may partly counteract the negative effects of climate warming (Cornelissen et al., 2007). Additionally, Kumar et al. (2013) suggested that the impact of climate change on soil microbes in Arctic regions may be impossible to predict. Thus, more and deeper research is necessary in order to determine the role of soil freeze/thaw in land-atmosphere feedbacks.

\subsection{Potential influences of urbanization}

Data used in this study were obtained from meteorological stations in China. The majority of these stations were established in the 1950s and 1960s (Ma et al., 2009), and intentionally situated outside of cities in order to reduce the impact of human activities on meteorological observations, and thus weather forecasts. However, since the late 1970s, urban areas have expanded dramatically. Studies indicate that cities in China have expanded by 2 to 5 times in area during the past 30 years (Wang et al., 2012). Because of this, some of the Chinese meteorological stations are now located within urban areas. Hence, the immediate question is how many of the changes in the near-surface soil freeze detected during this study are due to natural variations in climate change versus the impact of human activities such as urban expansion. Detailed investigation of this issue is far beyond this study; however, we provide here some preliminary analysis using limited data.

To explore the impact of urbanization on the near-surface soil freeze, we used data and information of urban expansion in China from 1990 through 2010 (Wang et al., 2012). The urban areas were manually identified using Landsat TM/ETM+ in the 1990s, 2000s and 2010s. The identification was mainly performed by three experienced operators and revised by high-resolution images in Google Earth ${ }^{\mathrm{TM}}$. The interpreted urban areas were finally integrated using sta-

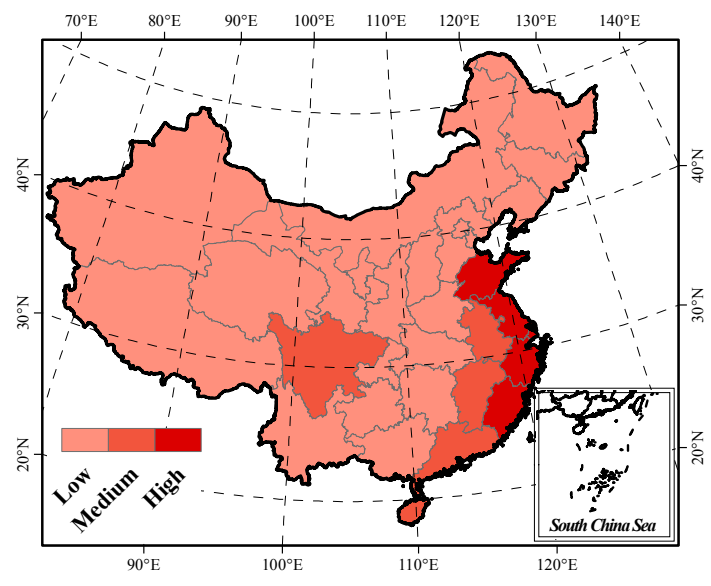

Figure 10. Rates of urban expansion from the 1990s through to the 2010s in China (modified from Wang et al., 2012).

tistical data of urban areas in local official yearbooks (Wang et al., 2012).

Over the period from 1990 through 2010, three regions can be divided based upon different degrees of urbanization rates, i.e., low rate $(<200 \%)$, medium rate $(200-500 \%)$, and high rate $(>500 \%)$ of urban expansion (Fig. 10). We calculated the regional anomalies of the number of soil freeze days (Fig. 11). For all three regions, there were significant decreasing trends in the near-surface soil freeze days since 1956 (Fig. 11). For the low- and medium-rate regions, the trends in $\mathrm{NF}$ were approximately -0.19 to -0.18 day $\mathrm{yr}^{-1}$; while for the high-rate regions, the trend was about -0.27 days $\mathrm{yr}^{-1}$, approximately 42 to $50 \%$ higher than the other two regions. It showed a similar phenomenon to that shown in Fig. 6b. Meanwhile, interannual variations were also significantly large in high-rate regions (Fig. 11). Here we chose 1990 as the breakpoint because (1) urban expansion data begin in 1990 (Wang et al., 2012), and (2) 1990 was close to the breakpoint shown in Fig. 6a.

We found that NF changed in a statistically non-significant manner in all three regions before 1990, and significantly decreased after 1990 (Fig. 11). The NF decreased sharply and continuously even though air temperature has a warming hiatus since approximately 1998 worldwide (Easterling and Wehner, 2009). Further analysis indicated that after 1990, $\mathrm{NF}$ in the regions with the lower rate of urban expansion decreased at a rate of about 0.85 day $\mathrm{yr}^{-1}$, while NF in regions with a high rate of urban expansion showed a statistically non-significant change over the same period (Fig. 10).

Based on these results, regions with high expansion rates had a significant long-term (1956-2006) decreasing trend in NF, while regions with low and medium expansion rates show a significant decrease in NF but their magnitudes were reduced almost by one-third (Fig. 11). This is because the regions with the high urban expansion rates are large cities along the east coast of China. These regions have been 

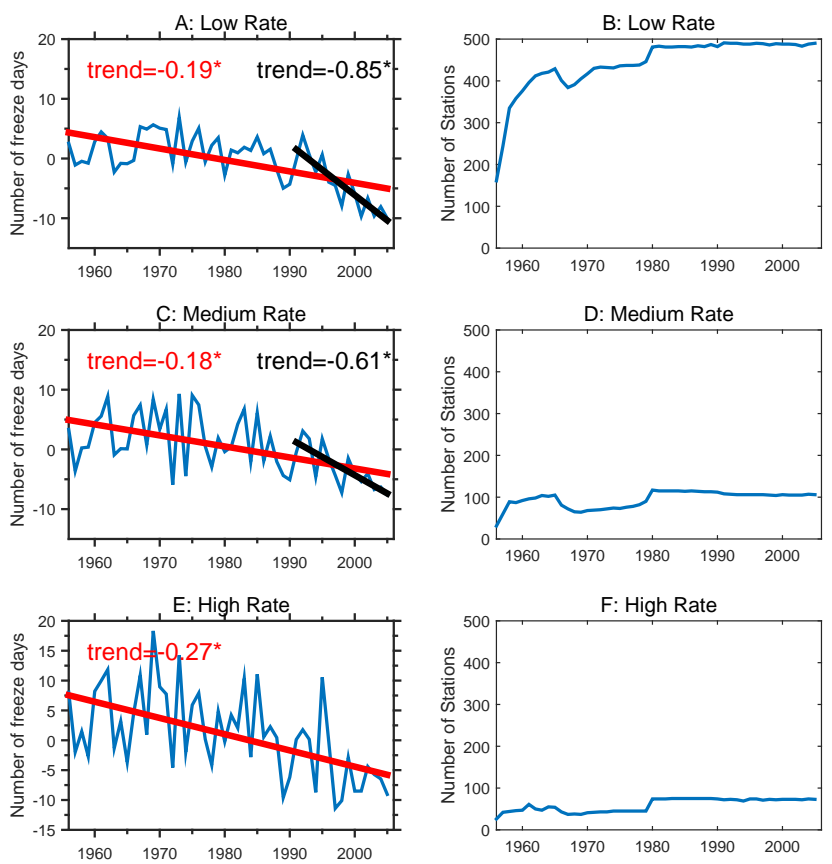

Figure 11. Regional changes of number of days (NF) in regions with different urbanization rates (left panels, i.e., $\mathbf{a}, \mathbf{c}$, and e). Black lines and red lines depict the linear regression for the period after 1990 and the period since 1956, respectively. Asterisk indicates a statistically significant trend at a $95 \%$ confidential level or higher. Right panels (b, d, and $\mathbf{f}$ ) are the number of stations used to create each time series.

relatively more developed since the mid 1950 s, resulting in a greater long-term impact of urban expansion over the past 5 decades on the near-surface soil freeze, superimposed on long-term climate warming. Over the period from 1990 through 2006, the trend in NF was not statistically significant $(P>0.05)$, probably due to climate warming hiatus, while the urban effect may be minimal because the urban expansion mainly occurred around the edges of the large cities and meteorological stations were not moved. For regions with low and medium expansion rates, the long-term decrease trends in NF may mainly reflect the impact of climate warming, with a relatively limited urban expansion effect because these regions are located far inland and are less developed. Meteorological stations in these regions were installed in the 1950s and are generally located several kilometers away from small and medium cities to avoid an urban effect on meteorological observations. However, over the period from 1990 through 2006, the magnitude of the decreasing trends in NF increased sharply (Fig. 11). This may be because the urban boundary was close to and probably far beyond the meteorological stations, resulting in substantial heat island impacts on the nearsurface soil freeze.

\subsection{Relationship with snow cover, North Atlantic Oscillation and Arctic Oscillation}

Snow cover may be an important contributor to the nearsurface soil freeze/thaw states in Arctic or pan-Arctic regions. The data used in this study reflected snow surface temperature when the ground surface was fully snow covered. In this case, it was simply assumed that the near-surface soil under the snow is in a frozen state. This assumption is valid because the minimum requirement for the existence of snow on ground is that the ground surface temperature be at or below the freezing point (Zhang et al., 2003). It is possible that soil may not freeze in places where snow cover starts early in autumn, and is relatively thick due to the snow insulation effect (Zhang, 2005). Meanwhile, because of the effect of a monsoon climate over the Eurasian continent, winter precipitation (snowfall) accounts for a very small fraction of the annual precipitation in China; thus, the influence of snow cover on the near-surface soil freeze-thaw status is very limited.

We examined the relationship between the long-term winter (December through February) North Atlantic Oscillations (NAO) and the freeze/thaw parameters in this study. Preliminary results indicated that there is a statistically significant negative relationship between the winter NAO and the duration of the near-surface soil freeze $(P<0.05)$ over the study period. We found that a higher winter NAO index corresponds to a shorter duration of the near-surface soil freeze over China. The first date of the near-surface soil freeze in autumn is positively correlated with the coming January NAO index $(P<0.05)$, indicating that the late near-surface soil freeze corresponds to a higher January NAO index. The number of days of the near-surface soil freeze is also negatively correlated with the February Arctic Oscillation (AO) index $(P<0.05)$, showing that the NF decrease corresponds to a higher February AO index. These results are consistent with shorter DR, less NF, and late FD corresponding to higher winter NAO and/or AO indexes.

We further conducted a correlation analysis between the monthly NAO/AO and the annual freezing index of air temperature, and between the monthly NAO/AO and the MAAT (July-June). The preliminary results show that NAO/AO indexes are positively correlated with the MAAT and negatively correlated with the freezing index of air temperature during winter months. These results further demonstrate that higher NAO/AO indexes correspond to warmer winters over China. These results are also consistent with changes in the shorter DR, less NF, and late FD found in our study.

\section{Summary}

Changes in the timing and duration (the first date, last date, duration, and number of days) of the near-surface soil freeze across China were investigated using ground-based observations at 636 meteorological stations from 1956 through 2006. 
We also investigated the response of changes in the timing and duration of the near-surface soil freeze to the mean monthly, seasonal, and annual air temperature, freeze index of air temperature and urban expansions across China during the past few decades.

The timing and duration of the near-surface soil freeze changed significantly from 1956 through 2006 across China. The first date of the near-surface soil freeze was delayed by about 5 days $\left(0.10 \pm 0.03\right.$ day $\left.\mathrm{yr}^{-1}\right)$. The last date of the near-surface soil freeze has occurred by about 7 days earlier

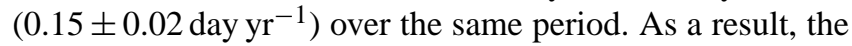
duration of the near-surface soil freeze decreased by about 12 days, and the number of the near-surface soil freeze days decreased by about 10 days $\left(0.20 \pm 0.03\right.$ day $\left.\mathrm{yr}^{-1}\right)$ for the period 1956-2006.

The changes in the timing and duration of the nearsurface soil freeze were accompanied by changes in air temperature. The first freeze date was delayed by about $3.86 \pm 0.52$ day ${ }^{\circ} \mathrm{C}^{-1}$ with increasing mean autumn (September through November) air temperature, and the last date of freeze advanced by about $2.82 \pm 0.72$ day ${ }^{\circ} \mathrm{C}^{-1}$ with mean spring (March through May) air temperature. As a result, the duration and number of days of the near-surface soil freeze were negatively correlated with mean annual air temperature while positively correlated with freeze index of air temperature. The duration of the near-surface soil freeze was shortened at a rate of $7.75 \pm 1.31$ day ${ }^{\circ} \mathrm{C}^{-1}$, while the number of days of the near-surface soil freeze decreased at a rate of $6.61 \pm 1.06$ day ${ }^{\circ} \mathrm{C}^{-1}$, which is about $15 \%$ less than that of the duration trend.

Urban expansion during the past few decades may also play a role in the changes of the timing and duration of the near-surface soil freeze. The rates of change since the early 1990s were approximately 4 times larger than the average rates from 1956 through 2006. Since the early 1990s, cities in China have expanded by approximately 2 to 5 times in urban area. The heat island effect may play a significant role in the timing and duration of the near-surface soil freeze. We found that changes in the timing and duration of the nearsurface soil freeze in areas with low rates of urban expansion were about one-third larger than those in areas with high rates of urban expansion, indicating that the heat island effect in small cities was greater than that in larger cities.

Acknowledgements. We wish to thank the anonymous reviewers and editor for their insightful and constructive critiques and suggestions which helped to improve this paper. This study was funded by the National Key Scientific Research Program of China (grant no. 2013CBA01802) and the National Natural Science Foundation of China (grant no. 91325202). The SRTM DEM data used in Fig. 1 were obtained from website http://srtm.csi.cgiar.org/.

Edited by: S. Gruber

\section{References}

Anandhi, A., Perumal, S., Gowda, P., Knapp, M., Hutchinson, S., Harrington Jr.,, J., Murray, L., Kirkham, M., and Rice, C.: Longterm spatial and temporal trends in frost indices in Kansas, USA, Climatic Change, 120, 169-181, doi:10.1007/s10584-013-07944, 2013.

Barichivich, J., Briffa, K. R., Myneni, R. B., Osborn, T. J., Melvin, T. M., Ciais, P., Piao, S., and Tucker, C.: Large-scale variations in the vegetation growing season and annual cycle of atmospheric $\mathrm{CO}_{2}$ at high northern latitudes from 1950 to 2011, Global Change Biol., 19, 3167-3183, doi:10.1111/gcb.12283, 2013.

Cherkauer, K. A. and Lettenmaier, D. P.: Hydrologic effects of frozen soils in the upper Mississippi River basin, J. Geophys. Res.-Atmos., 104, 19599-19610, doi:10.1029/1999JD900337, 1999.

CMA: Daily surface climatic dataset in China, China Meteorological Data Sharing Service System, Beijing, China, http://cdc.cma. gov.cn/ (last access: 08 July 2008), 2007a.

CMA: Specifications for surface meteorological observation, Part 13: Measurement of soil temperature, China Meteorological Press, Beijing, China, 2007b.

Cornelissen, J. H. C., Van Bodegom, P. M., Aerts, R., Callaghan, T. V., Van Logtestijn, R. S. P., Alatalo, J., Stuart Chapin, F., Gerdol, R., Gudmundsson, J., Gwynn-Jones, D., Hartley, A. E., Hik, D. S., Hofgaard, A., Jónsdóttir, I. S., Karlsson, S., Klein, J. A., Laundre, J., Magnusson, B., Michelsen, A., Molau, U., Onipchenko, V. G., Quested, H. M., Sandvik, S. M., Schmidt, I. K., Shaver, G. R., Solheim, B., Soudzilovskaia, N. A., Stenström, A., Tolvanen, A., Totland, Ø., Wada, N., Welker, J. M., Zhao, X., and Team, M. O. L.: Global negative vegetation feedback to climate warming responses of leaf litter decomposition rates in cold biomes, Ecol. Lett., 10, 619-627, doi:10.1111/j.14610248.2007.01051.x, 2007.

David, F.: Statistical models: theory and practice (revised version), Cambridge University Press, Cambridge, UK, 2009.

DeConto, R. M., Galeotti, S., Pagani, M., Tracy, D., Schaefer, K., Zhang, T., Pollard, D., and Beerling, D. J.: Past extreme warming events linked to massive carbon release from thawing permafrost, Nature, 484, 87-91, doi:10.1038/nature10929, 2012.

Easterling, D. and Wehner, M.: Is the climate warming or cooling?, Geophys. Res. Lett., 36, L08706, doi:10.1029/2009GL037810, 2009.

Edwards, K. A. and Jefferies, R. L.: Inter-annual and seasonal dynamics of soil microbial biomass and nutrients in wet and dry low-Arctic sedge meadows, Soil Biol. Biochem., 57, 83-90, doi:10.1016/j.soilbio.2012.07.018, 2013.

Entekhabi, D., Njoku, E. G., Houser, P., Spencer, M., Doiron, T., Yunjin, K., Smith, J., Girard, R., Belair, S., Crow, W., Jackson, T. J., Kerr, Y. H., Kimball, J. S., Koster, R., McDonald, K. C., O’Neill, P. E., Pultz, T., Running, S. W., Jiancheng, S., Wood, E., and Van Zyl, J.: The hydrosphere State (hydros) Satellite mission: an Earth system pathfinder for global mapping of soil moisture and land freeze/thaw, IEEE T. Geosci. Remote, 42, 21842195, doi:10.1109/TGRS.2004.834631, 2004.

Gilichinsky, D. and Wagener, S.: Microbial life in permafrost: A historical review, Permafrost Periglac., 6, 243-250, doi:10.1002/ppp.3430060305, 1995.

Heimann, M. and Reichstein, M.: Terrestrial ecosystem carbon dynamics and climate feedbacks, Nature, 451, 289-292, 2008. 
Henry, H. A. L.: Climate change and soil freezing dynamics: historical trends and projected changes, Climatic Change, 87, 421-434, doi:10.1007/s10584-007-9322-8, 2008.

John, R.: Mathematical statistics and data analysis, 3rd Edn., Cengage Learning, USA, 2006.

Jones, P. and Hulme, M.: Calculating regional climatic time series for temperature and precipitation: methods and illustrations, Int. J. Climatol., 16, 361-377, doi:10.1002/(SICI)10970088(199604)16:4<361::AID-JOC53>3.0.CO;2-F, 1996.

Kimball, J. S., McDonald, K. C., and Zhao, M.: Spring Thaw and Its Effect on Terrestrial Vegetation Productivity in the Western Arctic Observed from Satellite Microwave and Optical Remote Sensing, Earth Interact., 10, 1-22, doi:10.1175/EI187.1, 2006.

Koven, C. D., Ringeval, B., Friedlingstein, P., Ciais, P., Cadule, P., Khvorostyanov, D., Krinner, G., and Tarnocai, C.: Permafrost carbon-climate feedbacks accelerate global warming, P. Natl. Acad. Sci. USA, 108, 14769-14774, doi:10.1073/pnas.1103910108, 2011.

Kumar, N., Grogan, P., Chu, H., Christiansen, C., and Walker, V.: The Effect of Freeze-Thaw Conditions on Arctic Soil Bacterial Communities, Biology, 2, 356-377, doi:10.3390/biology2010356, 2013.

Li, X., Jin, R., Pan, X., Zhang, T., and Guo, J.: Changes in the near-surface soil freeze-thaw cycle on the QinghaiTibetan Plateau, Int. J. Appl. Earth Obs., 17, 33-42, doi:10.1016/j.jag.2011.12.002, 2012.

Lloyd, J. and Taylor, J.: On the temperature dependence of soil respiration, Funct. Ecol., 8, 315-323, doi:10.2307/2389824, 1994.

Ma, L., Zhang, T., Frauenfeld, O. W., Ye, B., Yang, D., and Qin, D.: Evaluation of precipitation from the ERA-40, NCEP-1, and NCEP-2 Reanalyses and CMAP-1, CMAP-2, and GPCP-2 with ground-based measurements in China, J. Geophys. Res., 114, D09105, doi:10.1029/2008JD011178, 2009.

Mastepanov, M., Sigsgaard, C., Dlugokencky, E. J., Houweling, S., Strom, L., Tamstorf, M. P., and Christensen, T. R.: Large tundra methane burst during onset of freezing, Nature, 456, 628-630, doi:10.1038/nature07464, 2008.

Menzel, A., Jakobi, G., Ahas, R., Scheifinger, H., and Estrella, N.: Variations of the climatological growing season (1951-2000) in Germany compared with other countries, Int. J. Climatol., 23, 793-812, doi:10.1002/joc.915, 2003.

Niu, G.-Y. and Yang, Z.-L.: Effects of Frozen Soil on Snowmelt Runoff and Soil Water Storage at a Continental Scale, J. Hydrometeorol., 7, 937-952, doi:10.1175/JHM538.1, 2006.

Park, H., Sherstiukov, A. B., Fedorov, A. N., Polyakov, I. V., and Walsh, J. E.: An observation-based assessment of the influences of air temperature and snow depth on soil temperature in Russia, Environ. Res. Lett., 9, 064026, doi:10.1088/17489326/9/6/064026, 2014

Polyakov, I. V., Bekryaev, R. V., Alekseev, G. V., Bhatt, U. S., Colony, R. L., Johnson, M. A., Maskshtas, A. P., and Walsh, D.: Variability and Trends of Air Temperature and Pressure in the Maritime Arctic, 1875-2000, J. Climate, 16, 2067-2077, 2003.
Rempel, A. W.: Hydromechanical Processes in Freezing Soils, Vadose Zone J., 11, doi:10.2136/vzj2012.0045, 2012.

Schimel, J. P. and Mikan, C.: Changing microbial substrate use in Arctic tundra soils through a freeze-thaw cycle, Soil Biol. Biochem., 37, 1411-1418, doi:10.1016/j.soilbio.2004.12.011, 2005.

Schuur, E. A., Vogel, J. G., Crummer, K. G., Lee, H., Sickman, J. O., and Osterkamp, T. E.: The effect of permafrost thaw on old carbon release and net carbon exchange from tundra, Nature, 459, 556-559, doi:10.1038/nature08031, 2009.

Sinha, T. and Cherkauer, K. A.: Time Series Analysis of Soil Freeze and Thaw Processes in Indiana, J. Hydrometeorol., 9, 936-950, doi:10.1175/2008JHM934.1, 2008.

Su, Z., Wen, J., Dente, L., van der Velde, R., Wang, L., Ma, Y., Yang, K., and Hu, Z.: The Tibetan Plateau observatory of plateau scale soil moisture and soil temperature (Tibet-Obs) for quantifying uncertainties in coarse resolution satellite and model products, Hydrol. Earth Syst. Sci., 15, 2303-2316, doi:10.5194/hess-152303-2011, 2011.

Tagesson, T., Mölder, M., Mastepanov, M., Sigsgaard, C., Tamstorf, M. P., Lund, M., Falk, J. M., Lindroth, A., Christensen, T. R., and Ström, L.: Land-atmosphere exchange of methane from soil thawing to soil freezing in a high-Arctic wet tundra ecosystem, Global Change Biol., 18, 1928-1940, doi:10.1111/j.13652486.2012.02647.x, 2012.

Wang, L., Li, C., Ying, Q., Cheng, X., Wang, X., Li, X., Hu, L., Liang, L., Yu, L, Huang, H., and Gong, P.: China's urban expansion from 1990 to 2010 determined with satellite remote sensing, Chin. Sci. Bull., 57, 2802-2812, 2012.

Yang, K., Qin, J., Zhao, L., Chen, Y., Tang, W., Han, M., Lazhu, Chen, Z., Lv, N., Ding, B., Wu, H., and Lin, C.: A Multiscale Soil Moisture and Freeze-Thaw Monitoring Network on the Third Pole, B. Am. Meteorol. Soc., 94, 1907-1916, doi:10.1175/BAMS-D-12-00203.1, 2013.

Zhang, T.: Influence of the seasonal snow cover on the ground thermal regime: An overview, Rev. Geophys., 43, RG4002, doi:10.1029/2004RG000157, 2005.

Zhang, T., Barry, R. G., Gilichinsky, D., Bykhovets, S., Sorokovikov, V., and Ye, J.: An amplified signal of climatic change in soil temperatures during the last century at Irkutsk, Russia, Climatic Change, 49, 41-76, doi:10.1023/A:1010790203146, 2001.

Zhang, T., Armstrong, R. L., and Smith, J.: Investigation of the nearsurface soil freeze-thaw cycle in the contiguous United States: Algorithm development and validation, J. Geophys. Res., 108, 8860, doi:10.1029/2003JD003530, 2003.

Zhang, Y., Li, B., and Zheng, D.: Datasets of the boundary and area of the Tibetan Plateau (DBATP), Global Change Research Data Publishing and Repository, doi:10.3974/geodb.2014.01.12.v1, last access: 16 December 2014. 